\title{
ВАРИАБЕЛЬНОСТЬ РИТМА СЕРДЦА ПРИ ОСЛОЖНЕННОМ ОЖИРЕНИИ
}

\author{
Смирнова Е.Н., Лоран Е.А., Шулькина С.Г.
}

ФГБОУ ВО «Пермский государственный медицинский университет имени академика Е.А.Вагнера» Минздрава России

На сегодняшний день показано, что наличие осложненного ожирения (ОО) ассоциируется с риском развития нарушения ритма сердца. Одним из факторов, способствующих развитию аритмий, является нарушение деятельности вегетативной нервной системы (BНC).

ЦЕЛЬ: изучить в сравнительном плане состояние функции вегетативной нервной системы у пациентов с различными формами осложненного ожирения (ОО).

МАТЕРИАЛЫ И МЕТОДЫ: в Исследование были включены 66 пациентов с ИМТ более 30 кг/м², сфор-

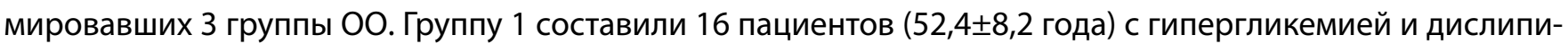
демией, но с нормальным уровнем АД, группу $2-23$ человека с АГ, дислипидемией, но нормогликемией, группу 3-37 пациентов с АГ, гипергликемией и дислипидемией. Группу сравнения составили 16 практически здоровых лиц (45,3 2,3 лет). Из Вариабельность ритма сердца изучалась на компьютерном электрокардиографе «Поли-Спектр Ритм 2012» компании «Нейрософт» и обрабатывалась при помощи программного обеспечения «Поли-Спектр.NET». Для оценки кратковременных стационарных записей ритмограмм использовался спектральный анализ, рассчитывали стандартные значения мощностей частотных составляющих спектра и временные параметры. Для выявление автономной нейропатии использовали 5 стандартных методик по D.Ewing.

PEЗУЛЬТАТЫ: в группе пациентов с ОО фоновая запись ритмограммы выявила достоверное снижение показателей временного анализа SDNN $(37,0$ против 50,5 в группе сравнения $p<0,05)$ и CV $(4,1$ и против 6,1 в группе сравнения $p<0,05)$, что свидетельствует о снижении общей вариабельности ритма сердца. При анализе спектральных показателей выявлено достоверное снижение общей мощности спектра у пациентов с ОО ТР (412,0 против 2434,0 в группе сравнения p<0,05), снижение мощности во всех частотных диапазонах. У пациентов с ОО парасимпатическая недостаточность регистрировалась в пробе с глубоким управляемым дыханием (патологические значения изменения чСС 8,0 против 14,0 в группе сравнения и р <0,05), в пробе с натуживанием (пограничные значения коэффициента Вальсальвы 1,64 и 1,35 соответственно, $p<0,05$ ) и в ортостатической пробе (снижение коэффициента 30/15 до 1,35 и 1,21 соответственно, p <0,05). Симпатическая недостаточность определялась по недостаточному приросту LF/HF в ортостатической пробе $(4,2$ и 2,7 соответственно $p<0,05)$. Анализ результатов не выявил разницы между группами ОО по временным и спектральным показателям ВРС (как по общей мощности спектра, так и по мощности во всех частотных диапазонах). Динамика LF/HF в группах: 1 гр. - 4,0; 2 гр. - 2,5; 3 гр. - 2,5; p >0,05;показатель К30/15 в 1 гр. - 1,20; 2 гр. - 1,21; 3 гр. - 1,21; p >0,05; Изменение ЧСС в пробе с глубоким управляемым дыханием 1 гр.-6,0; 2 гр. - 8,0; 3 гр. - 7,5 р >0,05; К Вальсальвы 1 гр. - 1,46; 2 гр. - 1,45; 3 гр. - 1,31; $p>0,05)$.

ВЫВОДЫ: для пациентов с ОО характерно снижение вариабельности ритма сердца, которое не зависит от компонентов метаболического синдрома.

Работа поддержана ГРАНТом РФФИ 17-44-590755. 